\title{
Potencialidades da análise documental para pesquisas sobre instituições de medida socioeducativa
}

\section{Potentialities of documental analysis for researches concerning institutions of socio-educative measures}

\author{
Juliana Vinuto Lima ${ }^{1}$
}

\begin{abstract}
Resumo
Pretende-se realizar neste trabalho um debate metodológico referente ao uso qualitativo da análise de documentos arquivísticos para pesquisas sobre instituições de controle de adolescentes que cometeram ato infracional. Nesse sentido, se exporá algumas definições sobre esta técnica metodológica para, posteriormente, realizar um balanço dos trabalhos nacionais que lançaram mão desta técnica ao analisar os relatórios institucionais de adolescentes em cumprimento de medida socioeducativa de internação, produzidos pela instituição com o intuito de informar o Judiciário sobre o comportamento e desenvolvimento do adolescente em questão. Por fim, se analisará os padrões de uso dessas pesquisas, a fim de problematizar as potencialidades e limites dessa técnica, além de sugerir novas formas de manuseio desse material.
\end{abstract}

Palavras-chave: Análise documental. Arquivos institucionais. Medida socioeducativa. Adolescentes. Lei. Métodos qualitativos.

\begin{abstract}
:
This work aims at executing a methodological debate concerning the qualitative usage of the analysis of file documents on researches about control institutions regarding adolescents who have committed an infraction. Therefore, some definitions on this methodological technique will be presented and, after that, a review of national works which have used this technique analyzing institutional reports of adolescents in confinement units - which are made by the institution aiming at informing the Judiciary Power about the behavior and the development of the teenager - will be done. At last, the pattern of usage of this technique on these researches will be analyzed, willing to problematize the potentialities and the limits of this technique and also to suggest new ways of handling this material.
\end{abstract}

Keywords: Documental analysis. Institutional files research. Socio-educative measure. Youth. Law. Qualitative methods.

\footnotetext{
${ }^{1}$ Mestre em Sociologia (2014) pela Universidade de São Paulo. Membro do Núcleo de Antropologia do Direito (NADIR-USP). E-mail: j.vinuto@gmail.com

Cad. de Pesq. Interdisc. em Ci-s. Hum-s., Florianópolis, ISSN 1984-8951

v.15, n.107, p. 197-214, ago/dez 2014
} 


\section{Consideraçoes iniciais}

Os adolescentes, quando considerados pelo Judiciário, como autores de ato infracional, podem ter que cumprir uma das medidas socioeducativas definidas pelo Estatuto da Criança e do Adolescente $(E C A)^{2}$, que implicam em formas diferenciadas de responsabilização e, portanto, de execução. Durante a medida socioeducativa de internação ${ }^{3}$ se produzem diversos documentos, dentre os quais relatórios nos quais constam pareceres sobre o adolescente internado e que são enviados ao Judiciário para a avaliação do mesmo. O objetivo desse artigo $^{4}$ é problematizar a existência desses relatórios institucionais, bem como realizar uma análise dos mesmos no intuito de compreender em que medida estes ajudam a construir a imagem do adolescente encarcerado.

O material a ser analisado aqui se refere à gestão das medidas socioeducativas em São Paulo. O espaço temporal no qual foram produzidos esses documentos - 1990 a 2006 - aborda a execução das medidas socioeducativas durante a gestão da Fundação Estadual para o Bem Estar do Menor de São Paulo (FEBEM-SP) pós-ECA, mostrando-se pertinente por abranger um cenário em que, pelo menos oficialmente, o âmbito normativo de atendimento ao adolescente em conflito com a lei foi alterado de forma diversa do âmbito administrativo. Em 1990, o ECA foi promulgado dentro de uma estrutura administrativa organizada a partir da Fundação Nacional do Bem-Estar do Menor (FUNABEM), instituição criada pela Lei Federal 4.513 de 01/12/1964, no início da Ditadura Militar, para o atendimento de adolescentes considerados em situação de ato infracional. Para a implementação das politicas relacionadas a esta questão também foram criados braços estaduais da FUNABEM, as FEBEMs. Ou seja, apesar da promulgação do ECA, até 2006 a FEBEM era administrativamente influenciada pelo marco legal anterior, sendo que apenas neste ano entra em cena o trabalho da Fundação Centro de Atendimento

\footnotetext{
${ }^{2}$ Segundo o artigo 103 do Estatuto da Criança e do Adolescente (ECA), ato infracional é a conduta descrita como crime ou contravenção penal, desde que realizada por jovens menores de 18 anos, já que, por serem inimputáveis penalmente, devem ser julgados num fórum de justiça especial.

${ }^{3}$ Verificada a ocorrência de um ato infracional, a autoridade competente poderá aplicar uma das medidas socioeducativas determinadas no próprio ECA, a saber: advertência, obrigação de reparar o dano, prestação de serviço à comunidade, liberdade assistida, semiliberdade e internação.

${ }^{4}$ Este artigo foi produzido a partir de pesquisa de mestrado concluída em 2014. Para maiores informações, ver VINUTO, 2014.
} 
Socioeducativo ao Adolescente (Fundação CASA). Apesar do universo de relatórios não incluir os anos posteriores a 2006, algumas informações poderão ser encontradas em relatórios cujo adolescente tenha dado entrada no sistema até 2006 e que teve outras entradas em anos posteriores, ou os casos em que a medida socioeducativa teve fim apenas após o início dos trabalhos da Fundação CASA, já que todas essas informações constarão no mesmo relatório. Mesmo havendo número limitado de relatórios com esse perfil, estes podem fornecer novas informações relativas a continuidades e transformações que possam ter ocorrido no período de transição na gestão FEBEM para Fundação CASA.

Os relatórios que serão analisados aqui fazem parte das Pastas e Prontuários, espécies de dossiês que detém informações sobre os adolescentes internados. Nestas Pastas e nestes Prontuários constam vários outros documentos além do relatório, como boletins de ocorrência policial, relatórios de audiências judiciais, formulários de ingresso na instituição, laudos médicos, documentos administrativos de transferência entre unidades ou de entrega do adolescente ao responsável, e demais documentos que foram produzidos em razão da inserção do adolescente na medida socioeducativa. Porém, não é uniforme a distribuição de todos esses documentos, ou seja, há pastas/prontuários em que há todos os documentos e vários relatórios a serem analisados, enquanto que em alguns casos a falta de documentos inviabiliza a compreensão do caso.

A organização das Pastas e Prontuários de todos os adolescentes que cumpriram medida de internação no estado de São Paulo formam um imenso arquivo situado no Núcleo de Documentação do Adolescente (NDA), situado no Centro de Pesquisa e Documentação (CPDoc) da Escola para Formação e Capacitação Profissional (EFCP) da Fundação $\mathrm{CASA}^{5}$, atual responsável por medidas de internação e semiliberdade no Estado de São Paulo, além de também ser responsável também pelo gerenciamento de todas esses documentos. Assim, o que se objetiva aqui é compreender os usos possíveis desse material arquivístico, discutindo seus limites e potencialidades.

\footnotetext{
${ }^{5}$ Para mais informações: ALVAREZ, Marcos; SCHRITZMEYER, Ana Lucia P.; SALLA, Fernando et all. Adolescentes em conflito com a lei: pastas e prontuários do "Complexo do Tatuapé" (São Paulo/ SP, 1990 - 2006). Revista Adolescência e Conflitualidade, n. 1, edição 1, 2009.
}

Cad. de Pesq. Interdisc. em Ci-s. Hum-s., Florianópolis, ISSN 1984-8951 v.15, n.107, p. 197-214, ago/dez 2014 


\section{A análise documental}

Mostra-se importante problematizar as formas de uso de arquivos institucionais como ferramenta de pesquisa, já que tais documentos devem ser localizados em seu contexto político e social mais amplo, bem como explicitados os processos e intenções de sua produção. Uma primeira ressalva necessária ao uso deste tipo de material é o fato de que tais documentos foram produzidos intencionando outra finalidade que não a pesquisa sociológica, e por isso devem ser tratados com muito cuidado pelo pesquisador, já que os próprios atores que produziram estes documentos estão implicados nos aparatos de controle social e tem intenções e objetivos específicos na produção do mesmo, o que deve ser considerado. Segundo Cellard há algumas limitações nas análises de qualquer material documental:

Se, efetivamente, a análise documental elimina em parte a dimensão da influência, dificilmente mensurável, do pesquisador sobre o sujeito, não é menos verdade que o documento constitui um instrumento que o pesquisador não domina. A informação, aqui, circula em sentido único; pois, embora tagarela, o documento permanece surdo, e o pesquisador não pode dele exigir precisões suplementares. (CELLARD, 2010, p. 295-296).

Diversos pesquisadores já problematizaram o método de análise documental e o utilizaram-nos nos mais variados tipos de trabalho, dado que o método demonstra vantagens significativas. Segundo Duranti:

(...) os materiais arquivísticos, ou registros documentais, representam um tipo de conhecimento único: gerados ou recebidos no curso das atividades pessoais ou institucionais, como seus instrumentos e subprodutos, os registros documentais são as provas primordiais para as suposições ou conclusões relativas a essas atividades e às situações que elas contribuíram para criar, eliminar, manter ou modificar. A partir destas provas, as intenções, ações, transações e fatos podem ser comparados, analisados e avaliados, e seu sentido histórico pode ser estabelecido. (DURANTI, 1994, p. 50).

Porém, por mais que esses documentos demonstrem algo, tais "provas" devem ser contextualizadas. Apesar de serem "leituras particulares dos eventos sociais" (MAY, 2004, p. 205), quando se trabalha com um material arquivístico, padronizado, que foi produzido durante longos anos, alguns pontos podem se mostrar recorrentes, e é necessário compreender as razões de tal recorrência. 
Nesse sentido, os documentos não são reflexos da realidade, "mas também constroem a realidade social e as versões dos eventos" (MAY, 2004, p. 213).

Para compreender o referido material arquivístico não como reflexo do que aconteceu no passado, mas como uma construção social constantemente reformulada, lanço mão do estudo de Aaron Cicourel (1968). O autor argumenta que as práticas organizacionais dos agentes podem ser uma chave de entendimento sobre as conexões entre os diferentes níveis da vida social e seus sistemas simbólicos. Em seu estudo sobre a organização da justiça juvenil, argumenta que o conhecimento tácito, aliado às descrições de experiências realizadas pelos mais diversos atores, fornece ampla margem de interpretação de certas regras formais, ressignificando tais formalidades ao transformá-las em regras práticas passíveis de serem utilizadas no cotidiano.

O argumento de fundo do autor é que é na rotina organizacional profissional que se pode perceber a padronização e a institucionalização de certos códigos de tipificação. Em um processo de socialização profissional, os atores criam categorias a partir de experiências diárias, mostrando-se necessário analisar o comportamento desses atores para se compreender como a instituição executa as suas atividades:

General procedural rules are laid down for members, and members develop and employ their own theories, recipes, shortcuts for meeting general requirements acceptable to themselves and tacitly or explicitly acceptable to other members acting as "supervisors" or some form of external control (CICOUREL, 1968, p.1) ${ }^{6}$.

Nesse sentido, há um conhecimento tácito, uma informação de fundo, algo que "todo mundo sabe", evidenciando uma seletividade de descrições que presume e utiliza tais expectativas de fundo, considerando apenas determinadas descrições a serem colocadas nos documentos como significativa, em detrimento de diversas outras possíveis. É esse conhecimento tácito que permite a tradução de informações oriundas de conversas e comportamentos em uma linguagem própria a relatórios escritos, sendo estes considerados como evidências. Compreendendo a tradução

\footnotetext{
${ }^{6}$ Tradução livre: "Regras processuais gerais são formuladas para os membros, e os membros desenvolvem e empregam suas próprias teorias, receitas, atalhos para atender aos requisitos gerais aceitáveis para si e tácita ou explicitamente aceitáveis para outros membros que atuam como "supervisores" ou alguma forma de controle externo".
} 
como $\mathrm{o}$ ato de fazer passar uma linguagem - existente em conversas e comportamentos - para outra - utilizada nos documentos -, percebe-se que há uma abertura possível nesta tradução, possibilitando a existência de várias construções do que acontecera na interação, sendo tais construções abertas à negociação pelas partes interessadas.

Tal contexto demonstra a necessidade de estudos que se esforcem em compreender a forma como regras abstratas são implementadas no cotidiano de trabalho desses atores, pois são essas regras que iluminam a compreensão sobre os documentos produzidos: "Specifying the ways in which the members of a community define or initiate, sustain, and alter imputations of competence, illness, and criminality, provides an empirical context for clarifying abstract jurisprudential concepts on the rule of law" (CICOUREL, 1968, p. 23).

Dado este contexto, verifica-se que tais registros documentais podem ser fontes preciosas de informação sobre as interações face a face. Não que nestes documentos constem as exatas informações do que ocorreu na interação, mas, de alguma forma, são estes os dados selecionados, dentre vários outros possíveis, como importantes e significativos a serem informados ao Judiciário.

\subsection{Análises documentais como técnica para compreender a medida socioeducativa de internação.}

Nesta sessão se objetiva expor alguns trabalhos que se utilizaram da análise de arquivos existentes em instituições executoras de medida socioeducativa de internação, após a promulgação do ECA, a fim de perceber alguns padrões de emprego desse material ${ }^{8}$. A forma de exposição de tais trabalhos será cronológica, a partir da data de defesa da tese ou dissertação, no caso de trabalhos acadêmicos, ou de publicação, quando se tratar de livros. Vale lembrar que, mais do que uma

\footnotetext{
${ }^{7}$ Tradução livre: "Especificando as maneiras pelas quais os membros de uma comunidade definem ou iniciam, mantém e alteram imputações de competência, doenças e criminalidade, fornece-se um contexto empírico para esclarecer conceitos abstratos jurisprudenciais sobre o Estado de Direito".

${ }^{8}$ Vale lembrar que na era FEBEM as crianças supostamente abandonadas, bem como qualquer criança que fosse considerada problemática, também poderiam ser internadas. Porém, neste trabalho priorizou-se trabalhos que focassem a análise em adolescentes considerados como em conflito com a lei. Para maiores informações sobre as crianças internadas por motivos não ligados a atos infracionais, ver BERNAL, 2004.
}

Cad. de Pesq. Interdisc. em Ci-s. Hum-s., Florianópolis, ISSN 1984-8951

v.15, n.107, p. 197-214, ago/dez 2014 
tentativa de esgotar as obras em questão, se esforçará aqui para discutir o tratamento metodológico dado a esse material documental institucional.

Um primeiro trabalho a ser exposto aqui que lançou mão da referida técnica foi a dissertação de mestrado em História Social produzida por Gutemberg Alexandrino Rodrigues, cujo título é Os filhos do mundo: a face oculta da menoridade (1964-1979), defendida em ano de $2000^{9}$. O objetivo do autor neste trabalho é entender as terminologias criadas para justificar a institucionalização de crianças e adolescentes. Para isso, Rodrigues trabalha com as informações de 385 prontuários da FEBEM-SP produzidos em 3 unidades específicas entre anos de 1976 e 1979, período dos primeiros trabalhos da FEBEM-SP. Nesse momento da pesquisa, houve dois tipos de análise: uma a partir dos pareceres dos funcionários da FEBEM, e outro a partir de levantamento quantitativo de dados dos adolescentes, como idade, sexo, local de moradia, motivo da internação, etc. O autor apresenta dados quantitativos, utilizando frases encontradas em relatórios institucionais para ilustrar os dados expostos. E para a confrontação do discurso oficial e a prática efetuada na FEBEM, Rodrigues visualiza as informações dos prontuários sob a luz de duas outras fontes de informação: os discursos de Mário Altenfelder, que atuou como primeiro presidente da FUNABEM, entre os anos de 1964 a 1974, e que também atuou como secretario da promoção social de São Paulo na época em que nasceu a FEBEM-SP; e os textos publicados por diversos colaboradores na Revista Brasil Jovem, periódico da FUNABEM que teve 40 edições entre 1967 e 1978.

A partir dos resultados de sua pesquisa de campo, Rodrigues defende que a FEBEM possuiu seus próprios ideólogos cotidianos, notadamente os pareceristas dos adolescentes, que atuam como assistentes sociais, psicólogos e psiquiatras, cujas ideias concordavam grandemente com o pensamento normatizador de Altenfelder e dos colaboradores da Brasil Jovem, contribuindo todos para o processo de estigmatização dos menores no final do século XX:

Os pareceres da Fundação Estadual do Bem-Estar do Menor, aliado aos artigos de Brasil Jovem, mostraram que as teorias lombrosianas, as teorias eugênicas e excludentes, desenvolvidas ao longo do século XIX, não estavam soterradas: antes se mantiveram por meio do viés conservador e

\footnotetext{
${ }^{9}$ Apesar da dissertação de mestrado ter sido defendida em 2000, para a análise aqui realizada lançou-se mão da publicação da mesma pela Editora do IBCCrim, publicada em 2001.

Cad. de Pesq. Interdisc. em Ci-s. Hum-s., Florianópolis, ISSN 1984-8951

v.15, n.107, p. 197-214, ago/dez 2014
} 
autoritário que caracteriza grande parte da sociedade. (RODRIGUES, 2001, p. 277. Grifos no original).

Em 2001, Roberto da Silva defende outro trabalho em que lança mão de análise documenta ${ }^{10}$, desta vez em sua pesquisa de doutorado em Educação intitulado $A$ eficácia sócio-pedagógica da pena de privação da liberdade. Neste trabalho, Silva teve como objetivo examinar:

as variáveis que determinam a maior ou menor eficácia da pena aplicada, isto é, as condições que o Estado e a sociedade oferecem para a execução penal e os fatores capazes de intervir sobre ela, que podem fazer com que a pena atinja ou não as finalidades a ela atribuídas (SILVA, 2001, p. 14).

Para isso, o autor faz uma análise a partir de informações oriundas do que ele chama como "observação na vida real" ${ }^{11}$, além de trabalhar as informações encontradas nos prontuários dos indivíduos internados. Também desenvolve uma análise quantitativa a partir de questionários respondidos por 240 pessoas em 4 instituições de internação do estado de São Paulo, sendo 60 entrevistados em cada uma das seguintes unidades: Internato Encosta Norte, uma unidade da FEBEM; Penitenciária de Franco da Rocha, cujos internos são homens adultos em regime semi-aberto ou fechado, Penitenciária Feminina do Butantã, para mulheres em

\footnotetext{
${ }^{10}$ Em sua pesquisa de mestrado, Silva também lança mão de análise documental, mas com foco em crianças consideradas órfãs e abandonadas, e por isso não consta neste balanço bibliográfico (SILVA, 1996).

${ }_{11}$ Roberto da Silva passou 24 anos em instituições de internação, e por isso a especificidade de sua trajetória Ihe fornece muitas informações, que raramente outro pesquisador poderia conseguir. Antes de ser internado em um abrigo público para crianças aos 2 anos de idade, passou fome e morou nas ruas com sua mãe e seus 3 irmãos, até o Juizado de Menores determinar a internação das crianças na FEBEM e da mãe em um hospital psiquiátrico, o que separou os membros da família. Como a FEBEM também atendia crianças abandonadas (ou no caso do autor, supostamente abandonadas), ficou internado por alguns anos sob esta condição, mas aos 12 anos, por desobedecer regras disciplinares, e não por praticar algum tipo de crime, foi transferido para uma unidade voltada para a internação de infratores, denominação utilizada na época para o que hoje se nomeia como adolescente em conflito com a lei. Aos 17 anos foi desinternado, mas não tinha contato com nenhum familiar, o que influenciou para a falta de referências e de apoio nesse processo de transição. Viveu nas ruas, praticou pequenos delitos, foi preso e passou 7 anos na Casa de Detenção de São Paulo. Nessa nova fase de sua vida, Roberto da Silva estudou Direito como autodidata, advogando em causa própria e conseguindo reduzir sua pena a um quinto da condenação. Em 1984, já em liberdade, continuou ajudando os que ficaram presos a defender seus direitos, e voltou a estudar aos 33 anos de idade, fazendo o supletivo de primeiro e segundo graus (o equivalente ao Ensino Fundamental e Médio), formou-se em Pedagogia pela Universidade Federal do Mato Grosso e tornou-se mestre em educação em 1996, e doutor em educação em 2001, ambos pela Universidade de São Paulo. Posteriormente Silva torna-se professor pela mesma instituição. O autor ressalta nesta obra que apenas na condição de pesquisador teve acesso às fontes de informação sobre seus irmãos, no arquivo morto da FEBEM, e só em 1996 os encontrou e pode conhecer suas trajetórias.
} 
regime fechado, e a Cadeia Pública de Bragança Paulista, voltada para homens adultos em custódia judicial (flagrante, provisórios e condenados, com regime fechado e semi-aberto). Também foram ouvidos os profissionais responsáveis pela elaboração dos referidos documentos, e o mesmo roteiro de entrevistas foi aplicado, de maneira não sistemática. Por fim, a partir das situações e legislações prisionais, nacional e internacional, o autor desenvolve um esforço em localizar as especificidades da situação brasileira e, mais especificamente, paulista.

Como foi possível observar, Silva analisa quatro tipos diferentes instituições de internação, pois, apesar de deterem especificidades diversas, permitem analisar a pena de privação de liberdade quando aplicada a diferentes segmentos da população, partindo do pressuposto de que há muitas semelhanças entre estes sistemas, como a dinâmica institucional, a natureza das relações interpares e os efeitos do processo de prisionização. Silva define a "eficácia sócio-pedagógica desejável da pena de privação de liberdade" enquanto um aprendizado decorrente da experiência de estar privado de liberdade:

A eficácia da pena de privação de liberdade consiste em dotar o indivíduo
preso de um aparato conceitual que Ihe permita apropriar-se de códigos,
símbolos e valores para tornar-se uma pessoa útil a si próprio, à sua família
e à sociedade, principalmente não voltando a delinquir, além de assegurar
os mínimos sociais básicos à sua sobrevivência em condições de
dignidade. (SILVA, 2001, p. 265).

Silva conclui que o sucesso ou fracasso das finalidades objetivas da pena deve-se à natureza e à qualidade das relações entre os diversos atores sociais inseridos neste contexto: "Minha conclusão, portanto, é que os saberes científicos atuantes dentro do sistema penitenciário, por omissão, no sentido em que aponto, ou por ação, no sentido apontado por Malaguti (1997) possuem significativa parcela de responsabilidade em relação ao baixo grau de resolução que a prisão tem na execução da pena de privação de liberdade" (SILVA, 2001, p. 330).

Já em 2005 foram produzidas duas pesquisas que se enquadram na proposta desta sessão. A primeira delas é a tese de doutorado em História defendida por Gutemberg A. Rodrigues, pesquisador já citado, intitulada As tramas do cárcere: a institucionalização de crianças, jovens e adultos (1979-1992), que teve como objetivo discutir como são tecidas o que o autor nomeia como "tramas do cárcere", 
responsáveis por legitimar, produzir e classificar determinados grupos sociais como delinquentes desde crianças.

\begin{abstract}
Partindo desses pressupostos, o objetivo fundamental desse trabalho é o de pensar como a figura do delinquente, do quasímodo, do monstro anormal, dentro de uma terminologia foucaultiana, é construída por uma miríade discursiva da qual constam agentes institucionais, agentes jurídicos, meios de comunicação, bem como representantes de outras esferas sociais. (RODRIGUES, 2005, p. 55).
\end{abstract}

Nesta pesquisa foram analisados prontuários produzidos entre 1979 e 1992, com foco naqueles cujos adolescentes na maioridade foram transferidos para presídios. Com este propósito, Rodrigues analisou 1.800 prontuários de três instituições voltadas para a internação de adolescentes ou adultos infratores. A partir das informações contidas nesses documentos, foram criado dois bancos de dados, que permitiram a análise quantitativa, além de trechos de documentos existentes nos prontuários, que foram utilizados para ilustrar suas argumentações. Em um dos bancos continha dados sobre o perfil dos internos, como idade, cor, ocupação, etc., e outro detinha informações dos pareceres dos técnicos da unidade, informações de $\mathrm{BO}$ e dos processos dos juízes de menores e das varas criminais. O autor também procurou, em todos os prontuários, cartas, recortes de jornais e revistas, redações dos internos, etc.

Neste contexto, Rodrigues argumenta que: "As duas instituições dialogavam constantemente, pois se iam adolescentes da FEBEM para os presídios, os presídios também enviavam adolescentes para a FEBEM" (2005, p. 78). Além disso, o autor conclui que existe uma mesma lógica argumentativa em todos os prontuários e em todas as instituições, na qual a terminologia dos pareceres buscava no ambiente de origem e em aspectos da personalidade alguns aspectos que justificassem a internação do adolescente. "Todos eram portadores de desvio de conduta, com percentil muito baixo, sentimento de desvalia, imaturidade, influenciabilidade. Exatamente dentro da linha das teses de Lombroso para o qual delinquente já nasce delinquente" (RODRIGUES, 2005, p. 161).

A outra pesquisa defendida em 2005 refere-se a uma dissertação de mestrado em História Social escrita por Silvia Coelho Hernandes, com o titulo Mãos para trás e cabeça baixa: tipologia documental dos prontuários das crianças e adolescentes internos da Febem/ SP (1938-2004). O primeiro contato da autora com 
os prontuários ocorreu em 1989, sendo que posteriormente teve oportunidade de trabalhar novamente com tais prontuários, em 1995, percebendo que poucas coisas tinham mudado desde então. Percebeu que o modelo dos prontuários novos em muito pareciam com os do começo do século, o que fez a autora se questionar se isso significaria semelhança também no atendimento desses adolescentes.

A técnica metodológica utilizada foi o levantamento de tipos documentais, analisando os prontuários produzidos entre 1938 a 2004, abarcando 915 documentos contidos em 14 prontuários distribuídos no espaço temporal proposto. A autora argumenta que os documentos inseridos no prontuário são muito parecidos e refletem as mesmas atividades:

Essa semelhança garante que uma amostra do todo tem a capacidade de
refletir o universo, por sua característica de homogeneidade. Essa
homogeneidade dispensa a análise da totalidade dos prontuários,
permitindo para o seu conhecimento, um prontuário a cada cinco anos
(HERNANDES, 2005, p. 99).

Escolhidos os prontuários, montou-se um banco de dados com informações de todos os documentos constantes no prontuário, assim como diversas informações sobre este, como tipo documental, ano de produção, setor produtor e destinatário, função, etc. A partir desta pesquisa Hernandes conclui que:

Os documentos que ali se encontram espelham essa atividade: prestação
de contas. A trajetória do interno desde a sua entrada, as transferências de
unidade ou instituição e a sua saída são minunciosamente comprovadas,
mas são raros os documentos que demonstram os acontecimentos durante
a permanência das crianças ou dos adolescentes. Os relatórios,
documentos que teriam como função relatar esses acontecimentos, o fazem
raramente, além disso, são elaborados tendo por base os valores dos
profissionais que lá trabalham. (HERNANDES, 2005, p. 123).

A autora argumenta que a forma de elaboração e a composição desses prontuários evidenciam uma escolha, pois é produto das relações estabelecidas e, portanto, carregado de intencionalidades, argumentando que nos prontuários não consta a história das crianças e adolescentes, pois não contém suas particularidades, mas apenas classificações padronizadas. Mas, ao contrário, ele só pode explicitar a relação entre diversas instituições responsáveis por este adolescente.

Em 2006 mais um trabalho nos quais tais prontuários de atendimento são estudados foi produzido. George W. Toledo defende a dissertação de mestrado em 
Psicologia com o titulo A delinquência juvenil no Estado de São Paulo: característica, frequência, evolução e tendências observadas entre os anos de 1950, 1960, 1979, 1985, 1995, 2000, 2001 e 2002. Seu objetivo foi o de estudar o fenômeno da delinquência no Estado de São Paulo, nos referidos anos, a fim de dispor de pelo menos um ano para cada década, focando nas características dos adolescentes em conflito com a lei, estimando as taxas de delitos de modo aferir a sua evolução no tempo e estimar sua tendência. A partir de informações contidas nos prontuários da FEBEM, Toledo procurou-se descrever o perfil dos adolescentes em conflito com a lei no espaço temporal citado, em termos de idade, escolarização e inserção no mercado de trabalho, analisando $10 \%$ do total dos prontuários, com exceção de 1950, ano em que se trabalhou com todos os prontuários produzidos, totalizando assim uma amostra de 2.432 prontuários, a partir das seguintes medidas socioeducativas: liberdade assistida, semi-liberdade e internação, pois acredita que este grupo, por ter recebido as medidas mais severas, "possui um envolvimento com práticas criminais mais significativas" (TOLEDO, 2005, p. 54). Os dados foram armazenados em um banco de dados, o que permitiu analisar o contexto nacional e compará-lo com pesquisas que trabalham as estatísticas relacionadas em outros países. Porém, o autor ressalta que as variáveis utilizadas na caracterização do adolescente em questão referem-se àquelas que foram privilegiadas pelo Núcleo de Documentação de Adolescentes da FEBEM/SP, local onde se encontravam os prontuários, não sendo possível saber quais referenciais teóricos que orientaram as escolhas dos técnicos responsáveis.

O autor disponibiliza os dados decorrentes de sua pesquisa através de gráficos e tabelas, concluindo que de fato houve o aumento na participação de jovens na prática de atos infracionais, bem como no número de delitos, cujo aumento não foi ocasionado pelo simples incremento da taxa populacional. No período houve uma melhora no grau de escolaridade desses adolescentes, porém para o autor isso não parece ser suficiente para diminuir tais taxas de participação em atos infracionais. O que parece ser fator importante é a defasagem escolar, demonstrando que estes adolescentes enfrentam dificuldades escolares e esta, por sua vez, parece não atender a demanda dos mesmos. Nesse sentido, a nãofrequência escolar se mostrou um fator de risco neste contexto, dado que a maioria 
dos jovens institucionalizados não estava matriculado na escola. Além disso, Toledo também conclui que exercer um trabalho ou emprego tem peso limitado neste contexto, dado que vários dos adolescentes internados estavam trabalhando no momento de entrada da FEBEM.

Por fim, o trabalho mais recente que será citado aqui tem é oriundo da pesquisa Adolescentes em conflito com a lei: pastas e prontuários do Complexo do Tatuapé (São Paulo/SP, 1990-2006), resultado de uma parceria entre o Núcleo de Estudos da Violência da Universidade de São Paulo (NEV-USP) e a Fundação Centro de Atendimento Socioeducativo ao Adolescente (Fundação CASA). Esta pesquisa teve como objetivo principal reconstruir os principais aspectos das atividades da FEBEM-SP, a partir das pastas e prontuários dos adolescentes que passaram pela instituição entre 1990 e 2006, portanto após a promulgação do ECA. Especificamente, essa pesquisa visou delinear o perfil socioeconômico dos adolescentes, caracterizar as medidas socioeducativas aplicadas e analisar o funcionamento das instituições da justiça juvenil, através da análise quantitativa dos dados.

A partir de um universo de 115.639 prontuários arquivados entre 1990 e 2006 foi calculada uma amostra aleatória de 1.576 prontuários, e para coletar os dados foram elaborados dois tipos de formulários: um formulário completo, que era utilizado para coletar os dados referentes a primeira e última entrada do adolescente na instituição, e um formulário reduzido, a ser utilizado para coletar informações sobre as demais entradas intermediárias, no caso do adolescente ter entrado mais de uma vez no sistema e, devido a isso, foram preenchidos 2.312 formulários. Informações sobre esta pesquisa foram apresentadas em diversas publicações e eventos (ALVAREZ; SCHRITZMEYER; SALLA et all., 2009; 2010; 2011) e desenvolve um levantamento de dados estatísticos a partir de informações sobre o perfil do adolescente, por exemplo, sexo, cor, nomes de pai e mãe como referenciais de sua vida familiar, etc.; tipos de infrações que mais motivaram a internação de tais adolescentes, a partir de períodos temporais, número de co-partícipes, etc.; entre diversos outros dados. Esses dados resultantes desta pesquisa documental são analisados à luz de outros tipos de dados de caráter nacional, como em pesquisas 
do IBGE ou do Censo Penitenciário, a fim de entender o perfil do adolescente comparado ao perfil brasileiro em geral.

\subsection{Padrões existentes no balanço bibliográfico}

Após a exposição dos referidos trabalhos, mostram-se mais claros os limites e potencialidades do uso de documentos arquivísticos para a compreensão das dinâmicas existentes na medida socioeducativa de internação.

$\mathrm{Na}$ maioria dos casos expostos, utilizam-se as informações existentes nas pastas e prontuários para análises quantitativas, sendo que alguns trechos existentes dos documentos são expostos para referendar esses dados. Acredita-se que a análise quantitativa desses dados, utilizados usualmente de forma descritiva, apenas é possível quando se destaca que tais informações não são necessariamente ligadas aos adolescentes internados, mas que se referem aos rótulos que os operadores do Direito e os funcionários que atuam em instituições de medida socioeducativa deram aos adolescentes com quem travaram contato. Essa afirmativa deve ser ressaltada, pois usualmente uma informação sobre o adolescente é alterada diversas vezes durante sua a trajetória entre as diferentes instâncias do sistema punitivo, como por exemplo, a cor da pele do adolescente ou nome do pai ou da mãe, etc. Essa divergência de informações ajuda a iluminar o argumento de que estas também são construídas socialmente, variando em grande medida a partir de quem escreve tais informações, bem como a relação deste com o adolescente internado em questão.

Justamente por conta dessa limitação quantitativa, acredita-se que o referido material arquivístico detém maior potencialidade quando analisado por técnicas qualitativas, pois permitem compreender as classificações existentes nos documentos, considerando também o contexto sócio-histórico, sendo tal contexto fonte potente de informação para analisar conjuntamente ao documento. Nesse sentido, num material que detém formas classificatórias recorrentes, que demonstra representações e práticas recorrentes, é necessário compreender as razões para tais recorrências, o que só pode ser entendido se considerarmos o contexto social mais amplo no qual estão inseridos tanto as referidas instituições, como os 
funcionários da mesma. Dessa forma, importa compreender esses documentos como tentativas de persuasão, já que nestes contam os motivos a partir dos quais o adolescente infracionou, as provas de que o adolescente está respondendo ou não ao trabalho institucional, as razões para que o mesmo continue ou finalize sua medida socioeducativa, demonstrações dos bons resultados do trabalho desenvolvido na Unidade, etc. Ou seja, de alguma forma, tais documentos reforçam a ideia da necessidade do trabalho dessas instituições, construindo uma versão dos casos, dentre diversas outras possíveis.

Porém, para desenvolver uma análise qualitativa apurada, deve-se estar atendo às pressuposições do pesquisador sobre as informações contidas nos prontuários. Por exemplo,

\begin{abstract}
Os prontuários se constituem em espécies de dossiês nos quais observamos toda a trajetória da institucionalização do menor, levanto-nos à impressão de que nada escapa aos olhos atentos da instituição encarregada de acompanhar todo o seu percurso, cujo ponto de partida se faz ainda no ambiente familiar, passando a acompanhar, paulatinamente, todos os atos, gestos identificadores de uma patologia a ser sanada. (RODRIGUES, 2001, p. 174).
\end{abstract}

Defende-se aqui que se deve partir de uma perspectiva diferente, pois atualmente é muito complicado dizer que "nada escapa aos olhos atentos da instituição". Na verdade, o que pode ser encontrado nestes arquivos são diversos tipos de informações repetidas, principalmente as relacionadas à família, não existindo análises realmente particulares. Nesse sentido, encara-se tais relatórios de forma próxima da defendida por Goffman (2010), já que há espaços de reserva da identidade que não são captados pelos funcionários da medida socioeducativa. Além disso, defende-se aqui que o relatório dá materialidade às representações sociais dos operadores do sistema de justiça e da execução da medida, e o que é selecionado por estes, no que se refere ao comportamento do adolescente, depende justamente de tais representações sobre os adolescentes com quem convivem cotidianamente. 


\section{Considerações finais}

O objetivo deste trabalho foi realizar uma discussão referente ao uso qualitativo da análise de documentos arquivísticos, com foco em pesquisas sobre instituições que executam a medida socioeducativa de internação que deve ser cumprida por adolescentes acusados de terem cometido determinados atos infracionais. Como foi exposto, há diversas pesquisas que já lançaram mão desta técnica metodológica, e intencionou-se aqui atualizar o debate dando exemplos da utilização da mesma, a fim de discutir alguns de seus limites e potencialidades.

Argumenta-se aqui que o principal limite da análise documental no tipo de estudo tratado neste artigo é a necessidade do cuidado metodológico de encarar os materiais arquivísticos como tentativas de convencimento, já quem os escreve pretende convencer seus leitores sobre a apropriação de seu ato ou seu parecer, sendo mais potente estudar as classificações construídas pelas instituições do que o suposto perfil dos próprios adolescentes internados. Pode-se observar que o relatório também é parte de uma relação social que tem níveis desiguais de poder, pois é uma avaliação, uma classificação, uma verdade, produzida por um ator que está ao lado da objetividade, portanto, fora de qualquer suspeita. A partir deste contexto pode-se compreender a produção do relatório como um exercício de saberpoder. A partir do que Foucault (2007) nomeia como exame, é possível discutir mais profundamente sobre as funções latentes deste documento, já que o processo de produção do relatório coloca em funcionamento relações de poder que constituem saberes, ou seja, que acabam por constituir um indivíduo como efeito e objeto de poder e de saber: "O exame combina as técnicas da hierarquia que vigia e as da sanção que normaliza. É um controle normalizante, uma vigilância que permite qualificar, classificar e punir. Estabelece sobre os indivíduos uma visibilidade através da qual eles são diferenciados e sancionados" (FOUCAULT, 2007, p. 154). Ou seja, é apenas porque o funcionário da medida socioeducativa detém o poder de produção do relatório que a tradução de comportamentos oriundos de distintas interações em informações oficiais é considerada válida, dado que este funcionário deteria o saber necessário para tal tradução. 
Porém, é importante ressaltar que, apesar dessa limitação a qual deve se atentar o pesquisador, a análise documental mostra-se como ferramenta imprescindível para compreender as formas classificatórias manejadas no cotidiano da instituição de medida socioeducativa, a fim de compreender melhor as relações e disputas de poder, bem como para avaliar em que medida o que consta na letra da lei é vivenciado pelos atores em sua rotina de trabalho dentro de uma instituição punitiva. Tais dimensões ainda merecem ser iluminadas para que seja possível analisar adequadamente a problemática estrutura-agência tanto no que se refere aos adolescentes encarcerados, quanto aos funcionários atuantes na instituição.

\section{Referências}

ALVAREZ, Marcos; SCHRITZMEYER, Ana Lucia P.; SALLA, Fernando et al (2009). Adolescentes em conflito com a lei: pastas e prontuários do "Complexo do Tatuapé" (São Paulo/ SP, 1990 - 2006). Revista Adolescência e Conflitualidade, n. 1, edição 1 p. X-XXI.

BERNAL, Elaine M. B. (2004). Arquivos do abandono: experiências de crianças e adolescentes internados em instituições do Serviço Social de Menores de São Paulo (1938-1960). São Paulo: Cortez.

BRASIL. Estatuto da Criança e do Adolescente (ECA). Lei n 8.069, de 13 de julho de 1990.

CELLARD, André (2008). A análise documental. In: Poupart, Jean et al. A pesquisa qualitativa: enfoques epistemológicos e metodológicos. Petrópolis: Vozes, p. 295-316.

CICOUREL, Aaron (1995). The social organization of juvenile justice. New Jersey: Transaction Publishers.

DURANTI, Luciana (1994). Registros documentais contemporâneos como provas de ação. Estudos Históricos, Rio de Janeiro, volume 7, número 13, p. 49-54.

FOUCAULT, Michel (2007). Vigiar e punir. Petrópolis: Vozes. 
GOFFMAN, Erving (2010). Manicômios, prisões e conventos. São Paulo: Perspectiva.

HERNANDES, Silvia Coelho (2005). Mãos para trás e cabeça baixa: tipologia documental dos prontuários das crianças e adolescentes internos da Febem/ SP (1938-2004). Dissertação de Mestrado. PPGHS/Universidade de São Paulo.

May, Tim (2004). Pesquisa social: questões, métodos e processos. Porto Alegre, RS: Artmed.

RODRIGUES, Gutemberg A (2001). Os filhos do mundo: a face oculta da menoridade (1964-1979). São Paulo: IBCCrim.

(2005). As tramas do cárcere: a institucionalização de crianças, jovens e adultos (1979-1992). Tese de Doutorado. PPGHS/Universidade de São Paulo, 2005.

SILVA, Roberto da (1996). A trajetória de institucionalização de uma geração de ex-menores: o processo de constituição da identidade delinquente em crianças órfãs e abandonadas. Dissertação de Mestrado PPGE/Universidade de São Paulo.

SILVA, Roberto da (2001). A eficácia sócio-pedagógica da pena de privação da liberdade. Tese de Doutorado PPGE/Universidade de São Paulo.

TOLEDO, George W (2006). A delinquência juvenil no Estado de São Paulo: característica, frequência, evolução e tendências observadas entre os anos de 1950, 1960, 1979, 1985, 1995, 2000, 2001 e 2002. Dissertação de Mestrado PPGP/Universidade de São Paulo.

VINUTO, Juliana (2014). Entre o "Recuperável” e o "Estruturado": classificações dos funcionários de medida socioeducativa de internação acerca do adolescente em conflito com a lei. Dissertação de Mestrado. PPGS/Universidade de São Paulo.

Artigo:

Recebido em: 11/05/2014

Aceito em: 11/12/2014 